\title{
Molecular rearrangements in longipinane derivatives
}

\author{
Pedro Joseph-Nathan and Carlos M. Cerda-Garcia-Rojas \\ Departamento de Quimica del Centro de Investigación y \\ de Estudios Avanzados, Instituto Politécnico Nacional, \\ Apartado 14-740, México, D.F., 07000 México.
}

\begin{abstract}
Suitable oxygen substituted $2,6,6,9$-tetramethyltricyclo[5.4.0.0 $\left.0^{2,8}\right]$ undec-9-ene (longipinene) derivatives or their saturated analogues, which are both isolated as esters from nature, can be transformed to several new ring-system containing molecules, which include 4,8,8-trimethyl-9-methyleneperhydro-1,5-methanonaphthalene, 4,8,8trimethyl-9-methylene-1, 2, 4a,5,6,7,8,8a-octahydro-1,5-meth anonaphthalene, 8,8,9-trimethyl-4-methyleneperhydro-1,3,5-methanonaphthalene, $2,6,6,11$-tetramethyltricyclo[5.4.0. $\left.0^{4,8}\right]$ undecane, $\quad 2,6,6,9$-tetramethyltricyclo $\left[5.4 .0 .0^{4,8}\right]$ undecane and 4,4,8,9-tetramethylperhydro-1,7-methanonaphthalene derivatives.
\end{abstract}

\section{INTRODUCTION}

Longipinenes deserve their name from the parent hydrocarbon, $\alpha-1$ ongipinene (1), described as a constituent of Pinus sylvestris (1). Compounds with this sesquiterpene skeleton and with different degrees of oxydation (2-3) have been found in stevia (2-6), Critonia (3), Polypteris (7) and Artemisia (8). During the last decade, we established the stereochemistry (5), absolute configuration (6) and conformation (6) of these structurally complex sesquiterpenes and described a full characterization of many of these molecules.

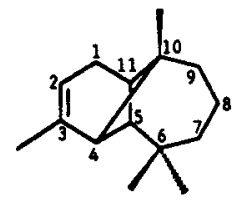

$\underline{1}$

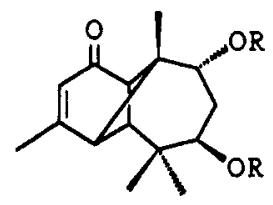

$\underline{2}$

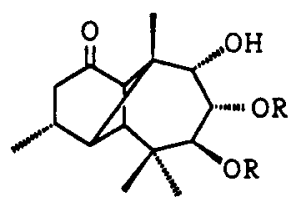

$\underline{3}$

Since these tricyclic strained longipinane and longipinene derivatives offer the possibility to generate new ring systems, because bond migration can be promoted to release the four-membered ring strain, we describe at present the transformation of compounds of types 2-3 into several new ring-system containing molecules. 
4,8,8-TRIMETHYL-9-METHYLENEPERHYDRO-1,5-METHANONAPHTHALENE AND 4,8,8-TRIMETHYL-9-METHYLENE-1, 2, 4a , 5, 6, 7, 8, 8a-OCTAHYDRO-1, 5-METHANONAPHTHALENE DERIVATIVES.

Treatment of 3 ( $R$ is angelate) with TsOH affords 4 ( $R$ is tiglate) in 93\% yield (9). Similarly 3 ( $R$ is acetate) was converted to 4 ( $R$ is acetate) in $89 \%$ yield by means of $\mathrm{BF}_{3} . E t_{2} \mathrm{O}$. However, when the $\alpha, \beta$-unsaturated carbonyl analogue of 3 ( $R$ is acetate) was treated under the latter reaction conditions, it afforded 5 in only $21 \%$ yield, while the conversion of the analogue of 3 ( $R$ is acetate) having the secondary methyl group with the $\beta$ configuration afforded 6 in 648 yield.

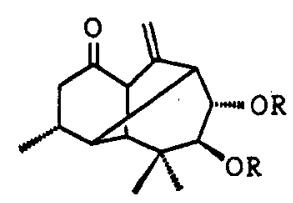

4

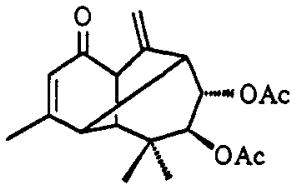

$\underline{5}$

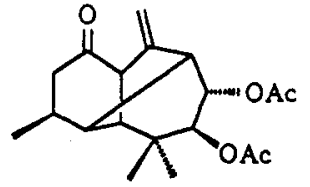

$\underline{6}$

When diol 7 was subjected to the molecular rearrangement with TsOH it afforded 8 in $36 \%$ yield and 9 in $54 \%$ yield.

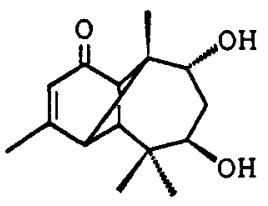

$\underline{7}$

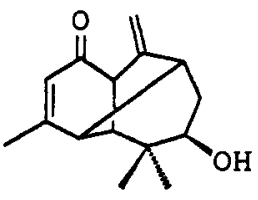

$\underline{8}$

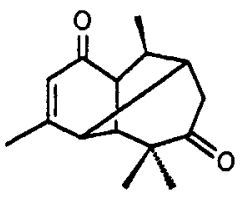

$\underline{9}$

The mechanism for the transformation of 7 to 8 and 9 involves the protonation of the c-9 hydroxyl group to provide the intermediate that meets the requirements for the antiperiplanar $c-4 / c-10$ bond migration. The tertiary carbonium ion at $c-10$ can eliminate a proton from the methyl group to yield 8 , or it can undergo an intramolecular transannular hydride migration assisted by the $c-7$ hydroxyl group to provide 9. This hydride migration was demonstrated by deuterium labeling.

8,8,9-TRIMETHYL-4-METHYLENEPERHYDRO-1,3,5-METHANONAPHTHALENE DERIVATIVE.

Suitable substituted longipinene derivatives can also be rearranged under basic reaction conditions.<smiles>COC1CC(OC)C2(C)C3C(C)=CC(=O)C3C1(C)C2(C)C</smiles>

$\underline{10}$

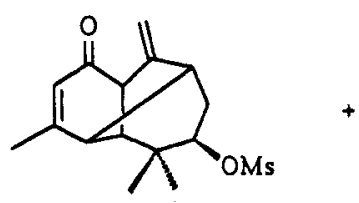

11

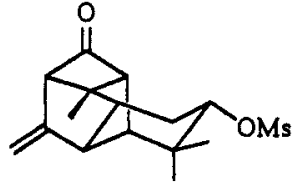

$\underline{12}$ 
Treatment of dimesylate 10 with $\mathrm{KOH}$ afforded the Wagner-Meerwein rearrangement product 11 in $26 \%$ yield, together with the further rearranged product 12 in $54 \%$ yield. The structure of 11 was tested by correlation with 8 , while that of 12 was verified by $x$-ray studies.

$2,6,6,11$-TETRAMETHYLTRICYCLO $\left[5.4 \cdot 0.0^{4,8}\right.$ ]UNDECANE DERIVATIVES.

Treatment of 13 with $\mathrm{KOH}$ provided the stereoisomers 14 and 15 in $58 \%$ and $21 \%$ yield, respectively. The structure and stereochemistry of both reaction products were determined by $x$-ray studies.

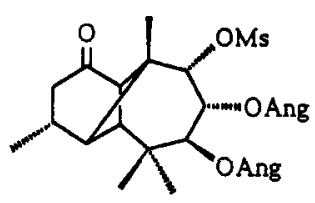

$\underline{13}$

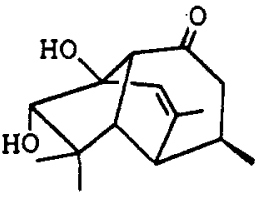

$\underline{14}$

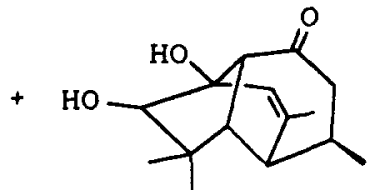

$\underline{15}$

A plausible reaction mechanism assumes the hydrolysis of the angelate groups followed by the subtraction of the proton from the 8-hydroxyl group. An oxygen assisted 1,2-hydride shift from $c-8$ to $c-9$ eliminates the mesylate group, to provide a 7-hydroxy-8-ketolongipinane. The 7-hydroxyl group epimerizes to a mixture of two compounds. Each of them can then loose a proton from $c-9$ and the $c-9$ carbanion can form a $c-9 /$ $c-10$ double bond with the simultaneous $c-10 / c-11$ bond migration to $c-11 / c-8$.

$2,6,6,9$-TETRAMETHYLTRICYCLO $\left[5,4,0.0^{4,8}\right.$ ]UNDECANE DERIVATIVE.

The double bond on the six-membered ring has a marked influence on the reaction outcome, as is evident when the unsaturated molecule 16 is treated under the basic reaction conditions.

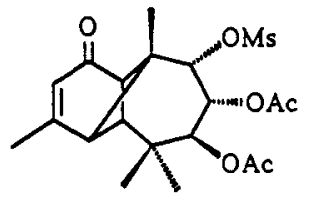

$\underline{16}$

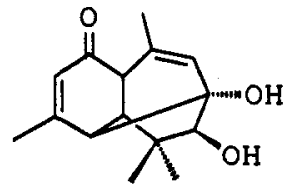

$\underline{17}$

In this case, 16 provides the single rearrangement product 17 in $67 \%$ yield. Here the $c-4 / c-10$ bond migrates to $c-4 / c-8$, instead of the $c-10 / c-11$ bond that migrates when a saturated six-membered ring is present. The structure and stereochemistry of the rearrangement product 17 was again verified by $\mathrm{X}$-ray analysis. 


\section{4, 4,8,9-TETRAMETHYLPERHYDRO-1,7-METHANONAPHTHALENE DERIVATIVE.}

The last molecular rearrangement we describe herein is again performed under acid conditions. Treatment of 3 ( $R$ is acetate) with $T s O H$ affords 4 ( $R$ is acetate) in $42 \%$ yield and the new skeleton containing compound 18 in $33 \%$ yield. Its structure and stereochemistry were established by $\mathrm{X}$-ray studies.

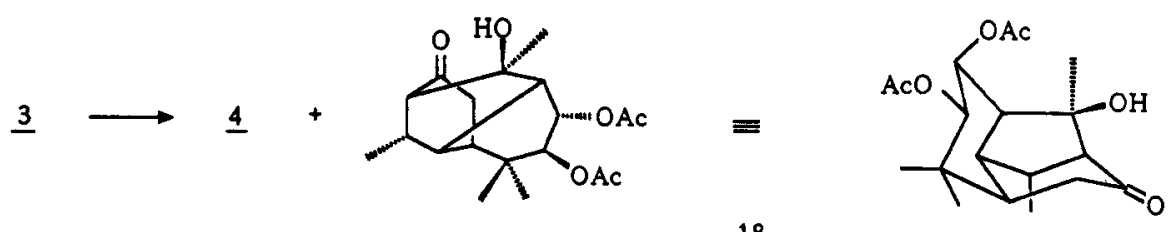

$\underline{18}$

The reaction mechanism for the transformation assumes the protonation of the 9-hydroxyl group followed by the antiperiplanar bond migration The derived C-10 carbonium ion can trap a molecule of water to provide the tertiary alcohol and the $c-10 / c-11$ bond can migrate to $c-2 / c-10$, which is also alpha to the carbonyl group.

Acknowledgements. Partial financial support from CoNaCyT (México) and from CoSNET (México) is acknowledged.

\section{REFERENCES}

1. H. Erdtman and L. Westfelt, Acta Chem. Scand., 17, 2351 (1963).

2. F. Bohlmann, C. Zdero and S. Schöneweis, Chem. Ber., 109, 3366 (1976).

3. F. Bohlmann, A. Suwita, A.A. Natu, H. Czerson and A. Suwita, Chem. Ber., 110, 3572 (1977).

4. L.U. Román, R.E. del Río, J.D. Hernández, P. Joseph-Nathan, V. Zabel and W.H. Watson, Tetrahedron, 37, 2769 (1981).

5. L.U. Román, R.E. del Río, J.D. Hernández, C.M. Cerda, D. Cervantes, R. Castañeda and P. Joseph-Nathan, J. Org. Chem., 50, 3965 (1985).

6. P. Joseph-Nathan, C.M. Cerda, R.E. del Rio, L.U. Román and J.D. Hernández, J. Nat. Prod., 49, 1053 (1986).

7. F. Bohlmann and C. Zdero, Chem. Ber., 108, 3543 (1975).

8. F. Bohlmann, N. Ates, J. Jakupovic, R.M. King and H. Robinson, Phytochem., 21, 2691 (1982).

9. L.U. Román, J.D. Hernández, R.E. del Rio, M.A. Bucio, C.M. Cerda-Garcia-Rojas and P. Joseph-Nathan, J. Org. Chem., 56, 1938 (1991). 